\title{
Microstructure and Coercivity of Nitrided Mn-Sn-Based Alloys
}

\author{
Masashi Matsuura ${ }^{1,2}$, Keita Isogai ${ }^{2}$, Keita Shinaji ${ }^{1}$, Nobuki Tezuka ${ }^{1}$ and \\ Satoshi Sugimoto ${ }^{1,2}$ \\ ${ }^{1}$ Department of Materials Science, Graduate School of Engineering, Tohoku University, \\ 6-6-02 Aoba-yama, Sendai, Miyagi 980-8579, Japan \\ ${ }^{2}$ Core Research for Evolutionary Science and Technology, Japan Science and Technology \\ Agency, 4-1-8 Honcho, Kawaguchi, Saitama 332-0012, Japan
}

\begin{abstract}
The microstructure of Mn-Sn-N and Mn-Sn-Co-N alloys was investigated by scanning electron microscopy and transmission electron microscopy (TEM). After the Mn-Sn alloy was annealed at $1000{ }^{\circ} \mathrm{C}$ under nitrogen, the coercivity increased to $245 \mathrm{kA} \cdot \mathrm{m}^{-1}$ and a lamellar structure appeared. The TEM images showed that the lamellar structure contained twins in the perovskite-type phase. After the Mn-Sn-Co alloy was annealed at $900{ }^{\circ} \mathrm{C}$ and subsequently annealed at $500{ }^{\circ} \mathrm{C}$ under nitrogen, the coercivity increased dramatically to $1270 \mathrm{kA} \cdot \mathrm{m}^{-1}$. A fine two-phase structure consisting of $\beta-\mathrm{Mn}$ and perovskite-type phases was observed, and some twins were present in the perovskite-type phases. In addition, a higher twin density was observed in the Mn-Sn-Co-N alloy than in the Mn-Sn-N alloy. These results indicate that the twins increased the coercivity of nitrided Mn-Sn based alloys.
\end{abstract}

Keywords: transition metal alloys and compounds, coercivity, microstructure, transmission electron microscopy

\section{Introduction}

Permanent magnets are used in numerous devices and are essential materials. However, no new types of permanent magnets have been developed since the discovery of Nd-Fe-B [1] and Sm-Fe-N [2] magnets. Coercivity is an important parameter for magnets; therefore, magnetic materials with high coercivity are particularly desirable. Some Mn-based compounds show high magnetic anisotropy. The $\tau$ phase in Mn-Al alloy has an $\mathrm{L}_{0}$ structure and shows a high anisotropy constant of about $10^{6} \mathrm{~J} \cdot \mathrm{m}^{-3}[3] . \mathrm{Mn}_{3} \mathrm{Ga}$ and $\mathrm{Mn}_{3} \mathrm{Ge}$ compounds are reported to have a $\mathrm{D}_{22}$ structure and to show high anisotropy constant of $1.2 \mathrm{MJ} \cdot \mathrm{m}^{-3}$ and $0.91 \mathrm{MJ} \cdot \mathrm{m}^{-3}$, respectively [4-6]. Furthermore, Mn alloys, such as Mn-N [7,8], Mn-Bi [9-11], Mn-Al-C [12,13], Mn-Ni-N [14], have been reported to show high coercivity. Therefore, Mn alloys have promising for obtaining high coercivity. Recently, our group reported that $\mathrm{Mn}-\mathrm{Sn}-\mathrm{N}$ and $\mathrm{Mn}-\mathrm{Sn}-\mathrm{Co}-\mathrm{N}$ alloys also show relatively high coercivity. Under a nitrogen atmosphere, $\mathrm{Mn}_{90} \mathrm{Sn}_{10}(\mathrm{at} \%)$ alloy was heat-treated at $1000{ }^{\circ} \mathrm{C}$ for $5 \mathrm{~h}$, and the coercivity reached $245 \mathrm{kA} \cdot \mathrm{m}^{-1}$ [15]. Our group has also 
reported that the addition of Co to the $\mathrm{Mn}-\mathrm{Sn}-\mathrm{N}$ alloy improves its magnetic properties, and our group has optimized the composition and preparation conditions of the Mn-Sn-Co-N alloy. Under a nitrogen atmosphere, $\mathrm{Mn}_{82.5} \mathrm{Sn}_{10} \mathrm{Co}_{7.5}$ (at\%) alloy was annealed at $900{ }^{\circ} \mathrm{C}$ (high-temperature annealing) and subsequently annealed at $400-700{ }^{\circ} \mathrm{C}$ (low-temperature annealing). The coercivity strongly depended on the low-temperature annealing and reached a maximum of $1270 \mathrm{kA} \cdot \mathrm{m}^{-1}$ for annealing at $500{ }^{\circ} \mathrm{C}$ [16]. However, the microstructure of the high-coercivity $\mathrm{Mn}-\mathrm{Sn}-\mathrm{N}$ and $\mathrm{Mn}-\mathrm{Sn}-\mathrm{Co}-\mathrm{N}$ alloys remained unclear. In the present study, we investigated the microstructure of the $\mathrm{Mn}-\mathrm{Sn}-\mathrm{N}$ and $\mathrm{Mn}-\mathrm{Sn}-\mathrm{Co}-\mathrm{N}$ alloys by scanning electron microscopy (SEM) and transmission electron microscopy (TEM).

\section{Experimental Procedure}

The $\mathrm{Mn}_{90} \mathrm{Sn}_{10}$ and $\mathrm{Mn}_{82.5} \mathrm{Sn}_{10} \mathrm{Co}_{7.5}$ alloys were fabricated by arc melting. The alloys were homogenized at $950-1000{ }^{\circ} \mathrm{C}$ under an argon atmosphere, and then crushed into pieces of 0.5-3 $\mathrm{mm}$ in diameter. The $\mathrm{Mn}$-Sn alloy was annealed at $1000{ }^{\circ} \mathrm{C}$ for $3-5 \mathrm{~h}$ under nitrogen and cooled to room temperature at a rate of $1{ }^{\circ} \mathrm{C} \cdot \mathrm{min}^{-1}$. The $\mathrm{Mn}$-Sn-Co alloy was annealed at $900{ }^{\circ} \mathrm{C}$ for $5 \mathrm{~h}$ (high-temperature annealing) and rapidly cooled to room temperature with a cooling jacket. The alloy was then annealed at $400-700{ }^{\circ} \mathrm{C}$ for $5 \mathrm{~h}$ (low-temperature annealing) and quenched to room temperature. The annealing process for the Mn-Sn-Co-N alloy is shown in Fig. 1.

The magnetic properties were measured by using a vibrating sample magnetometer (VSM) with a maximum applied field of $1.6 \mathrm{MA} \cdot \mathrm{m}^{-1}$. The initial magnetization curve and recoil loop in initial magnetization were measured under the maximum applied field. To evaluate the saturation magnetization and coercivity, the demagnetization curve was also measured by means of the VSM after applying a pulsed magnetic field of $6.4 \mathrm{MA} \cdot \mathrm{m}^{-1}$.

The phase was identified by X-ray diffraction (XRD) using $\mathrm{Cu}-\mathrm{K} \alpha$ radiation, and the microstructure was observed by SEM and TEM.

\section{Results and Discussion}

\subsection{Mn-Sn-N alloy}

The value of the saturation magnetization of the alloy annealed at $1000{ }^{\circ} \mathrm{C}$ under nitrogen, was increased from 13.1 to $77.9 \mathrm{mT}$, and also by annealing, the coercivity was increased from 15.9 to $245 \mathrm{kAm}^{-1}$. The $\beta$-Mn phase peaks were observed before annealing, and the $\mathrm{Mn}_{4} \mathrm{~N}$ and $\mathrm{Mn}_{3} \mathrm{SnN}$ phase peaks appeared in the XRD pattern after annealing [15]. Figure 2 shows the backscattered electron images of the Mn-Sn-N alloy before and after annealing at $1000{ }^{\circ} \mathrm{C}$ under nitrogen. Although there are a few black contrast regions, the majority of the image shows a homogeneous gray contrast for the sample before annealing (Fig. 2(a)). However, gray and white contrast lamellar patterns were observed for the annealed sample (Fig. 2(b)). Then, the lamellar structure was investigated by TEM.

Figure 3(a) and (b) show the brigt-field TEM images, and Fig. 3(c) shows the selected area diffraction (SAD) pattern taken from the annealed sample. The lamellar patterns, which were observed by SEM, were also observed by TEM. The regions with bright and dark contrasts in the TEM image of Fig. 3(a) correspond to the region with black and white contrasts in the SEM image of Fig. 2(b), respectively. The lamellar structures shown in Fig. 3(a) and (b) suggested the 
presence of stacking faults and twins, and this was confirmed by the SAD pattern (Fig. 3(c)). The SAD pattern corresponded to a perovskite-type phase, such as $\mathrm{Mn}_{4} \mathrm{~N}$ or $\mathrm{Mn}_{3} \mathrm{SnN}$, along the [110] zone axis. The SAD pattern shows a superposition of two fcc [110] zone diffraction patterns, which are symmetrical about the (111) mirror plane, indicating that the lamellar structure shown in the Fig. 3(a) and (b) consists of twins. In addition, diffraction spots arising from stacking faults, which are indicated by white arrows, were visible. Consequently, the coercivity of the Mn-Sn alloy system increased after annealing under nitrogen, and stacking faults and twins were introduced.

\subsection{Mn-Sn-Co-N alloy}

Figure 4 shows that the coercivity of the Mn-Sn-Co-N alloy strongly depended on the temperature of the low-temperature annealing. The coercivity reached a maximum value of 1270 $\mathrm{kAm}^{-1}$ after annealing at $500{ }^{\circ} \mathrm{C}$, and it then decreased as the annealing temperature increased. To understand the coercivity mechanism, the initial magnetization curve was measured. Figure 5 shows the initial magnetization curve of the alloy with a coercivity of $1270 \mathrm{kA} \cdot \mathrm{m}^{-1}$. Although the alloy was isotropic, an inflection point was observed in the curve at an applied field of about $1000 \mathrm{kA} \cdot \mathrm{m}^{-1}$. Thus, the recoil loop in the initial magnetization was measured. As shown in Fig. 6, the recoil loop is an irreversible and largely open curve. An open recoil loop is usually observed in magnets where the domain wall motion is pinned [17]. Therefore the coercivity mechanism of the high-coercivity Mn-Sn-Co-N alloy was found to be pinning of domain wall motion. In our previous report, the phase and microstructural changes in the alloy were reported [16]: the $\zeta$ ' phase (similar to $\left.\mathrm{MnN}_{0.48}\right)$ was converted to the $\beta$-Mn and perovskite-type $\left(\mathrm{Mn}_{4} \mathrm{~N}\right.$-like) phases by annealing at $500{ }^{\circ} \mathrm{C}$. In contrast, the $\zeta$ ' phase remained in the sample annealed at $700{ }^{\circ} \mathrm{C}$, and the $\beta-\mathrm{Mn}$ and perovskite-type phase peaks were small. Since the magnetic properties of the $\beta$-Mn phase is paramagnetic or weakly ferrimagnetic $[18,19]$, it is judged that the ferromagnetic phase is perovskite-type phase in the Mn-Sn-Co-N alloy.

Fig. 7 shows SEM images of the alloys annealed at 500 and $700{ }^{\circ} \mathrm{C}$. As reported in our previous paper [16], a fine two-phase structure exhibiting, white and black contrasts was observed in the alloy annealed at $500{ }^{\circ} \mathrm{C}$. In the XRD pattern of the alloy [16], there were peaks of $\beta$-Mn and perovskite-type phases. Therefore, the fine two-phase structure shown in Fig. 7(a) is thought to consist of $\beta$-Mn and perovskite-type phases. In the SEM image of the alloy annealed at $700{ }^{\circ} \mathrm{C}$, a coarse two-phase structure exhibiting black and white contrasts was observed. In this SEM image, another phase with gray contrast was also present. XRD analysis [16] showed that the $\zeta$ ' phase remained in addition to the $\beta$-Mn and perovskite-type phases in the alloy after annealing at $700{ }^{\circ} \mathrm{C}$. Therefore, the phases with white, black and gray contrasts in Fig. 7 (b) are thought to be the $\beta$-Mn, perovskite-type, and $\zeta$ ' phases, respectively. These results suggest that the fine two-phase structure is important in increasing the coercivity of the Mn-Sn-Co-N alloy. Therefore, the microstructure of the two-phase structure was investigated by TEM.

Figure 8 shows the TEM images and SAD patterns of the sample annealed at $500{ }^{\circ} \mathrm{C}$. The fine two-phase structure was observed (Fig. 8(a)), and the phases were identified by SAD. Figure 8(b) and (c) show the SAD patterns taken from the phases indicated by the black and white arrows in Fig. 8(a), respectively. The SAD pattern in Fig. 8(b) was identified as the $\beta$-Mn phase with a [012] zone axis. The SAD pattern of Fig. 8(c) corresponded to a perovskite-type phase 
with a [110] zone axis. In the SAD pattern shown in Fig. 8(c), the superposition of the two perovskite-type phases with [110] zone axis patterns, which were symmetrical about the (111) mirror plane, was observed. This result indicates the presence of twins in the perovskite-type phase. The magnified TEM image of the perovskite-type phase is shown in Fig. 8(d), and the TEM image shows some line patterns in the perovskite-type phase. These patterns also indicate the presence of twins in the perovskite-type phase. The crystal structure of the perovskite-type phase is cubic (space group number: 221), and crystal structure distortion of the perovskite-type phase was not observed by SAD analysis. Because magnetocrystalline anisotropy tends to depend on crystal structure, it is indicated that the perovskite-type phase does not have high uniaxial magnetocrystalline anisotropy.

As described above, the coercivity decreased drastically after annealing at $700{ }^{\circ} \mathrm{C}$, and the coarse two-phase structure was observed. Figure 9(a) shows a TEM image of the coarse two-phase structure. SAD analyses revealed that the coarse two-phase consisted of $\beta$-Mn and perovskite-type phases. The SAD pattern of Fig. 9(b) was taken from the perovskite-type phase with a [110] axis (black arrow, Fig. 9(a)). There are no obvious superposition spots in the pattern in Fig. 9(b) unlike in Fig. 8(c). Although some line patterns, which corresponds to twins, were observed in the perovskite-type phase in Fig. 9(a), the twin density of the alloy annealed at 700 ${ }^{\circ} \mathrm{C}$ was considerably lower than that of the alloy annealed at $500{ }^{\circ} \mathrm{C}$ (Fig 8(d)). At an annealing temperature of $500{ }^{\circ} \mathrm{C}$, grain growth of the perovskite-type and $\beta$-Mn phases tended to be inhibited in comparison with the alloy annealed at $700{ }^{\circ} \mathrm{C}$. In other words, twins in the perovskite-type phases are also divided finely. Therefore, the twin density can be higher in the alloy annealed at $500{ }^{\circ} \mathrm{C}$ than at $700{ }^{\circ} \mathrm{C}$.

In previous studies, it has been reported that twins can act as pinning sites [21-26]. Budruk et al. [22] observed that twins act as a pinning site for the domain wall in the Ni-Mn-Ga alloy system by using the Lorentz TEM technique. Isogai et al. [14] reported that the Mn-Ni-N system showed a relatively high coercivity of $352 \mathrm{kA} \cdot \mathrm{m}^{-1}$, and Sugimoto et al. [25] demonstrated the presence of twins in the Mn-Ni-N alloy, which had a high coercivity. Our results also mean that the twins can act as pinning sites of the domain wall motion and can increase the coercivity of the Mn-Sn-N and Mn-Sn-Co-N alloys.

\section{Summary}

We have investigated the microstructure of the Mn-Sn-N and Mn-Sn-Co-N alloys by SEM and TEM. Annealing the $\mathrm{Mn}_{90} \mathrm{Sn}$ alloy at $1000{ }^{\circ} \mathrm{C}$ under nitrogen increased the coercivity from 15.9 to $245 \mathrm{kA} \cdot \mathrm{m}^{-1}$, and a lamellar structure appeared. The TEM images showed that the lamellar structure contained stacking faults and twins in the perovskite-type phase of Mn-Sn-N alloy. After annealing the Mn-Sn-Co-N alloy at $900{ }^{\circ} \mathrm{C}$ and subsequently annealing at $500{ }^{\circ} \mathrm{C}$ under nitrogen, the coercivity increased dramatically, and it reached a maximum of $1270 \mathrm{kA} \cdot \mathrm{m}^{-1}$. In this sample, a fine two-phase structure consisting of $\beta-\mathrm{Mn}$ and perovskite-type phases was visible, and twins were observed in the perovskite-type phase. In addition, higher twin density was observed in the Mn-Sn-Co-N alloy with coercivity of $1270 \mathrm{kA} \cdot \mathrm{m}-1$ than in the Mn-Sn-N alloy with coercivity of $245 \mathrm{kAm}^{-1}$. The recoil curve in the initial magnetization of the Mn-Sn-Co-N alloy with the highest coercivity revealed that the coercivity mechanism was the pinning of domain wall motion. These results show that the twins can play an important role in 
increasing the coercivity of the alloys, and that higher twin density can also be an important factor in obtaining high coercivity.

\section{Acknowledgement}

This study was partially supported by JST-CREST and ESICMM. The authors would like to thank Dr. K. Kobayashi of Tohoku University for his assistance in TEM observation.

\section{References}

[1]. M. Sagawa, S. Fujimura, H. Yamamoto, and Y. Matsuura, Journal of Applied Physics, 55 (1984) 2083-2087.

[2]. J. M. D. Coey and H. Sun, Journal of Magnetism and Magnetic Materials, 87 (1990) L251-254.

[3]. A. J. J. Koch, P. Hokkeling, M. G. V. D. Sterg, and K. J. DeVos, Journal of Applied physics, 31, (1960) 75S.

[4]. F. Wu, S. Mizukami, D. Watanabe, H. Naganuma, M. Oogane, Y. Ando, and T. Miyazaki, Applied Physics Letters, 94 (2009) 122503 1-3.

[5]. H. Kurt, N. Baadji, K. Rode, M. Venkatesan, P. Stamenov, S. Sanvito, and J. M. D. Coey, Applied Physics Letters, 101 (2012) 132410 1-3.

[6]. B. Balke, G. H. Fecher, J. Winterlik and C. Felser, Applied Physics Letters, 90 (2007) 152504 1-3.

[7]. K. M. Ching, W. D. Chang, T. S. Chin and J. G. Duh, Journal of Applied Physics, 76 (1994) 6582-6584.

[8]. S. Nakagawa and M. Naoe, Journal of Applied Physics, 75 (1994) 6568-6570.

[9]. B. T. M. Willis and H. P. Rooksby, Proceedings of the Physical Society, B67 (1954) 290-296.

[10]. B. W. Roberts, Phycal Review, 104 (1956) 607-616.

[11]. T. Chen and W. E. Stutius, IEEE Transaction on Magnetics, MAG-10 (1974) 581-586.

[12]. H. Yamamoto, U. S. Patent 3, 661, 567.

[13]. T. Ohtani, N. Kato, S. Kojima, K. Kojima, Y. Sakamoto, I. Konno, M. Tsukahara and T. Kubo, IEEE Transaction on Magnetics, MAG-13 (1977) 1328-1330.

[14]. K. Isogai, H. Matsumoto and S. Sugimoto, Journal of Magnetism and Magnetic Materials, 310 (2007) e890-e892.

[15]. K. Isogai, K. Shinaji, T. Mase, M. Matsuura, N. Tezuka and S. Sugimoto, Materials Transaction, 54 (2013) 1236.

[16]. K. Shinaji, T. Mase, K. Isogai, M. Matsuura, N. Tezuka and S. Sugimoto, Materials Transaction, 54 (2103) 2007.

[17]. M. Dospial, D. Plusa and B. lusarek, Journal of Magnetism and Magnetic Materials, 324 (2012) 843.

[18]. R. Kohlhaas and W. D. Weiss, Zeitschrift für Naturforschung A, 24 (1968) 247.

[19]. V. Sliwko, P. Mohn and K. Schwarz, Journal of Physics Condensed Matter, 6 (1994) 6557.

[20]. T.B. Massalski, H. Okamoto, P. R. Subramanian and L. Kacprazak, Binally Alloy Phase Diagrams, Second Edition (ASM International, Materials Park, 1990), p 1208. 
[21]. M. J. Dospial, M. G. Nabialek, M. Szota, T. Mydlarz, K. Oźga and S. Lesz, J. Alloy. Comp., 536S (2012) S324-328.

[22]. A. Budruk, C. Phatak, A.K. Petford-Long, M. De Graef, Acta Materialia, 59 (2011) 4895-4906.

[23]. M.D. Graef, M. A. Willard, M. E. McHenry and Y. Zhu, IEEE Transaction on Magnetics, 37 (2001) 2663-2665.

[24]. S.P. Venkateswaran, N.T. Nuhfer, M.D. Graef, 55 (2007)5419-5427.

[25]. S. Sugimoto, K. Isogai, T. Hattori, H. Matsumoto, S. Yoshida and N. Tezuka, Physica status solidi, (c)4 (2007) 4573-4576. 


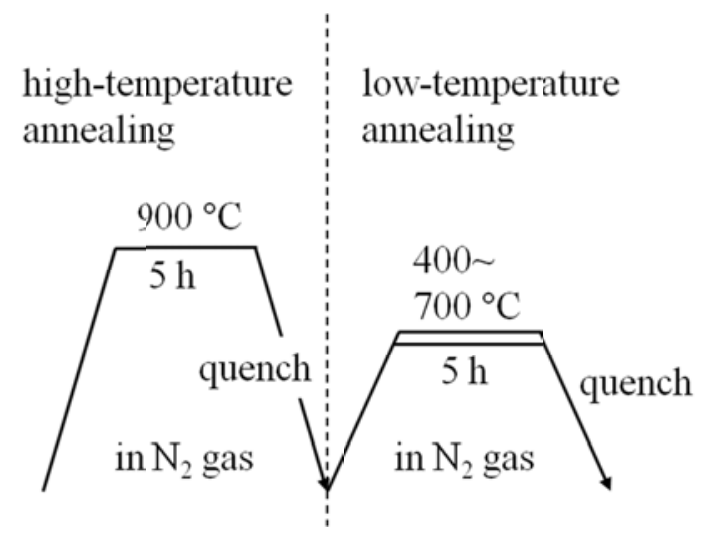

Fig. 1 Schematic image of the heat treatment process for $\mathrm{Mn}-\mathrm{Sn}-\mathrm{Co}-\mathrm{N}$ alloy 

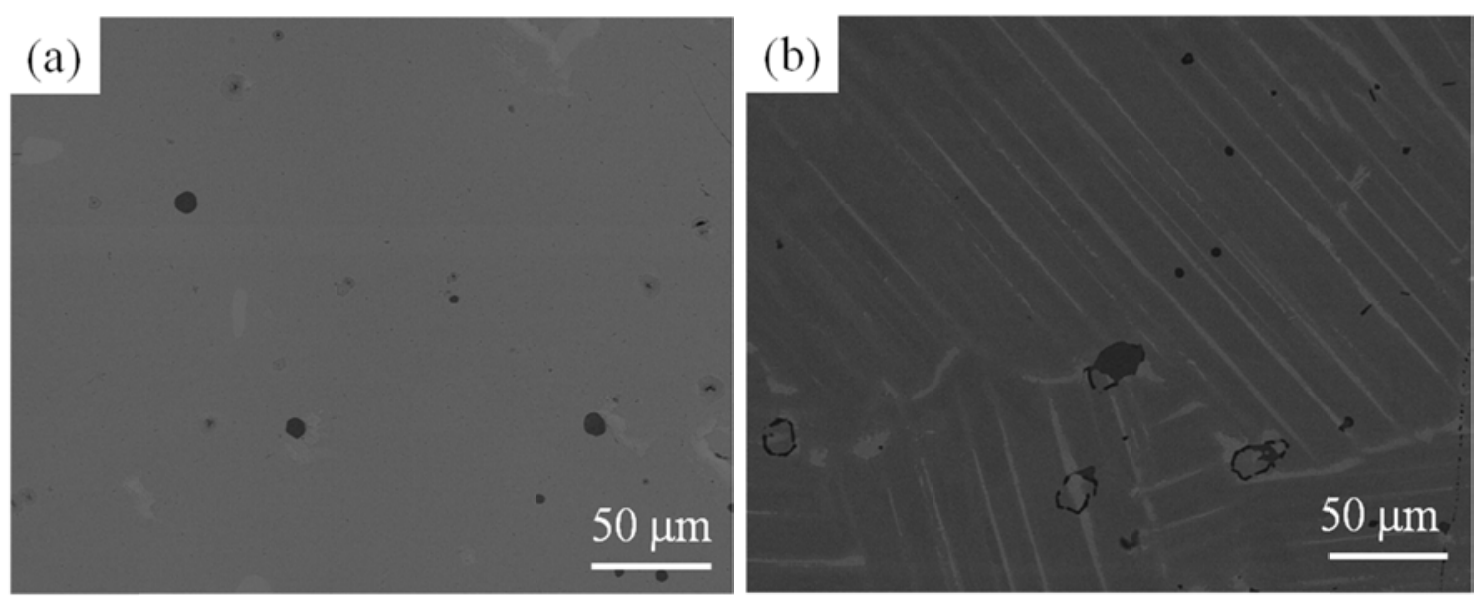

Fig. 2 Backscattered electron images of the Mn-Sn alloy (a) before and (b) after annealing at $1000{ }^{\circ} \mathrm{C}$ under nitrogen. 

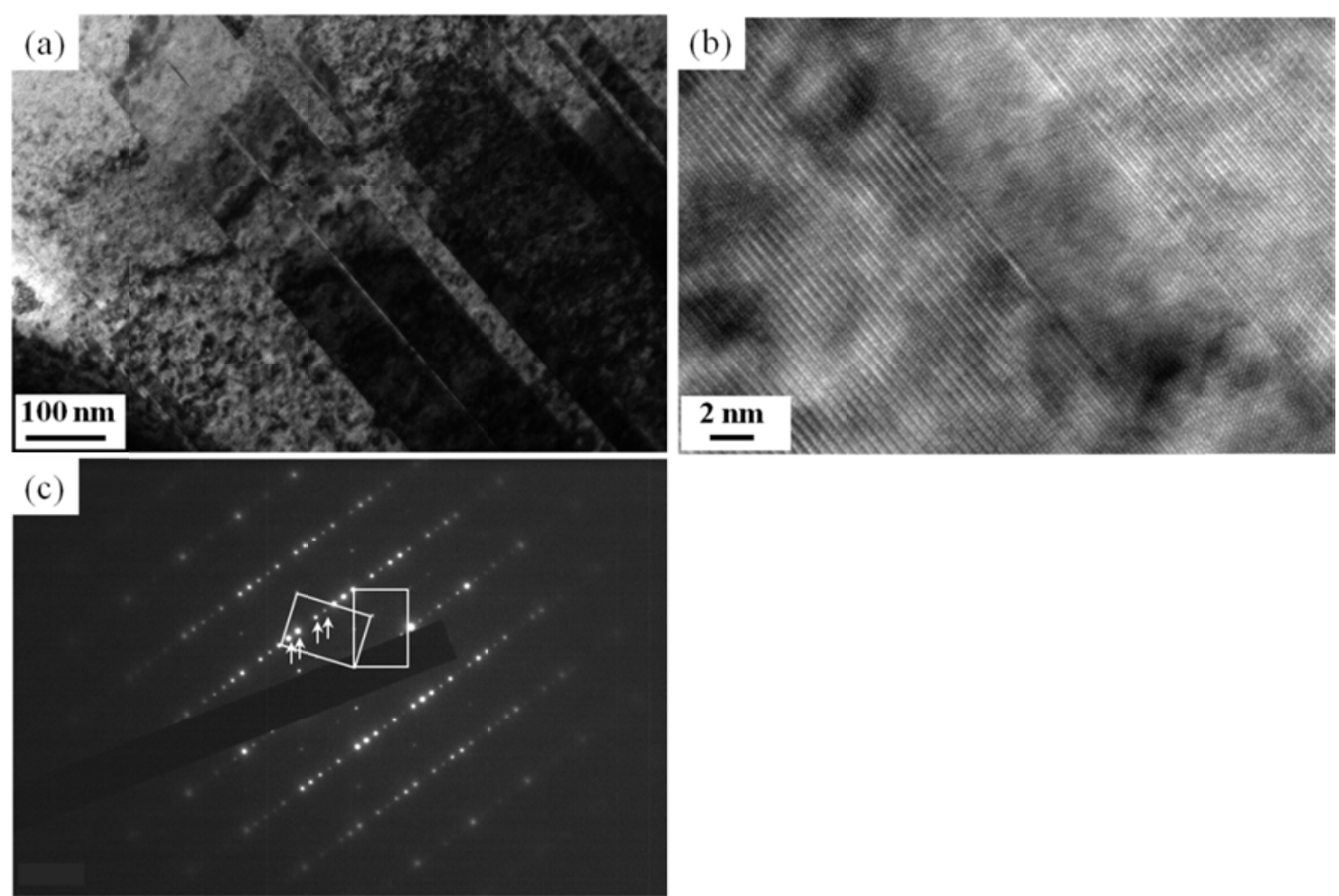

Fig. 3 (a),(b) Bright-field TEM images and (c) SAD pattern of the nitrided Mn-Sn alloy. Arrows indicate diffraction spots due to stacking faults. 


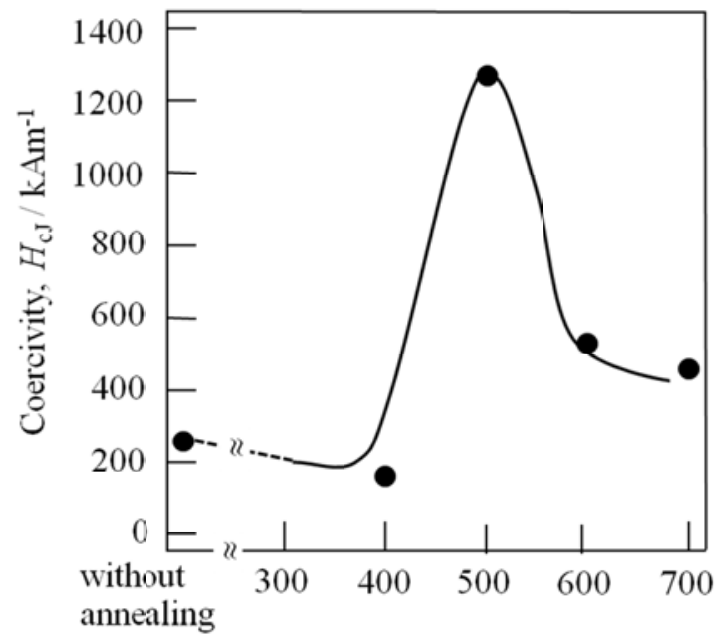

annealing temperature, $T_{\mathrm{a}} /{ }^{\circ} \mathrm{C}$

Fig. 4 Dependence of the coercivity of the $\mathrm{Mn}-\mathrm{Sn}^{-} \mathrm{Co}-\mathrm{N}$ alloy on the annealing temperature in the low-temperature annealing process. 


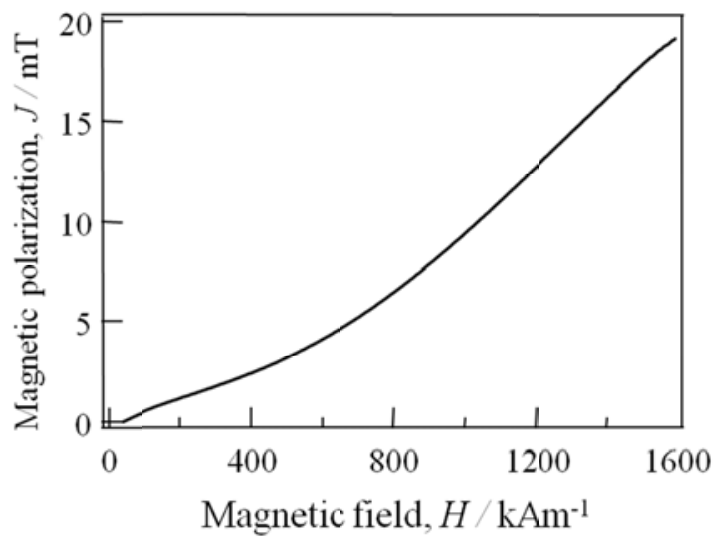

Fig. 5 Initial magnetization curve of $\mathrm{Mn}-\mathrm{Sn}-\mathrm{Co}-\mathrm{N}$ alloy with coercivity of $1270 \mathrm{kAm}^{-1}$. 


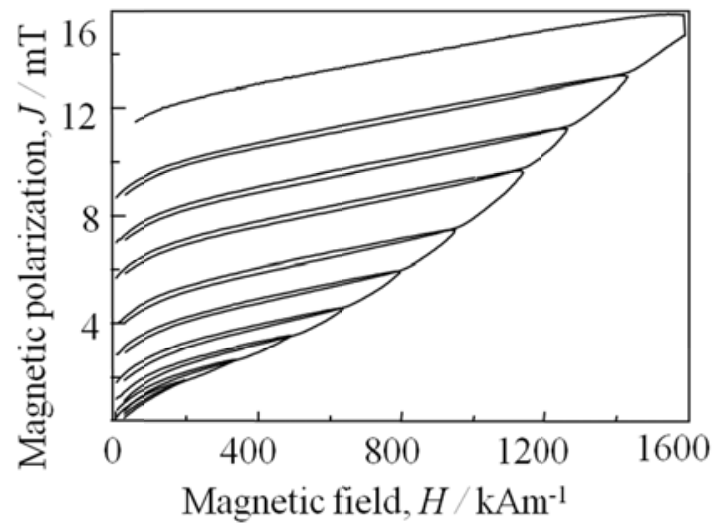

Fig. 6 Recoil loop in initial magnetization of the $\mathrm{Mn}-\mathrm{Sn}^{-} \mathrm{Co}-\mathrm{N}$ alloy with coercivity of $1270 \mathrm{kA} \cdot \mathrm{m}^{-1}$. 


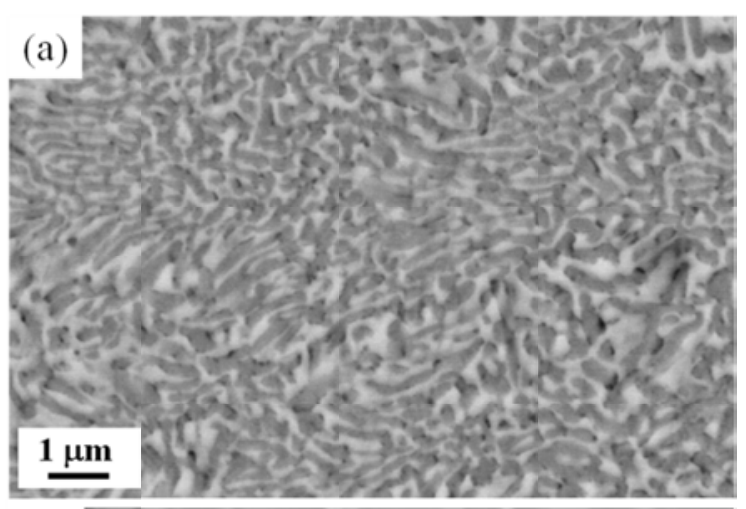

(b)

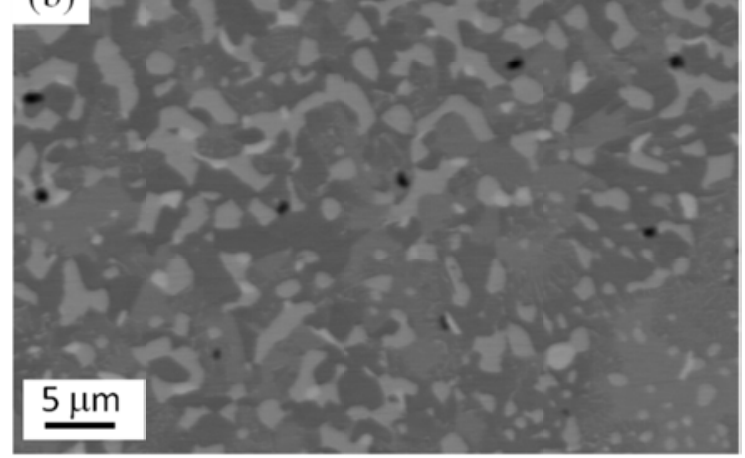

Fig. 7 SEM images of the Mn-Sn-Co-N alloys annealed at (a) $500{ }^{\circ} \mathrm{C}$, and (b) $700{ }^{\circ} \mathrm{C}$. 

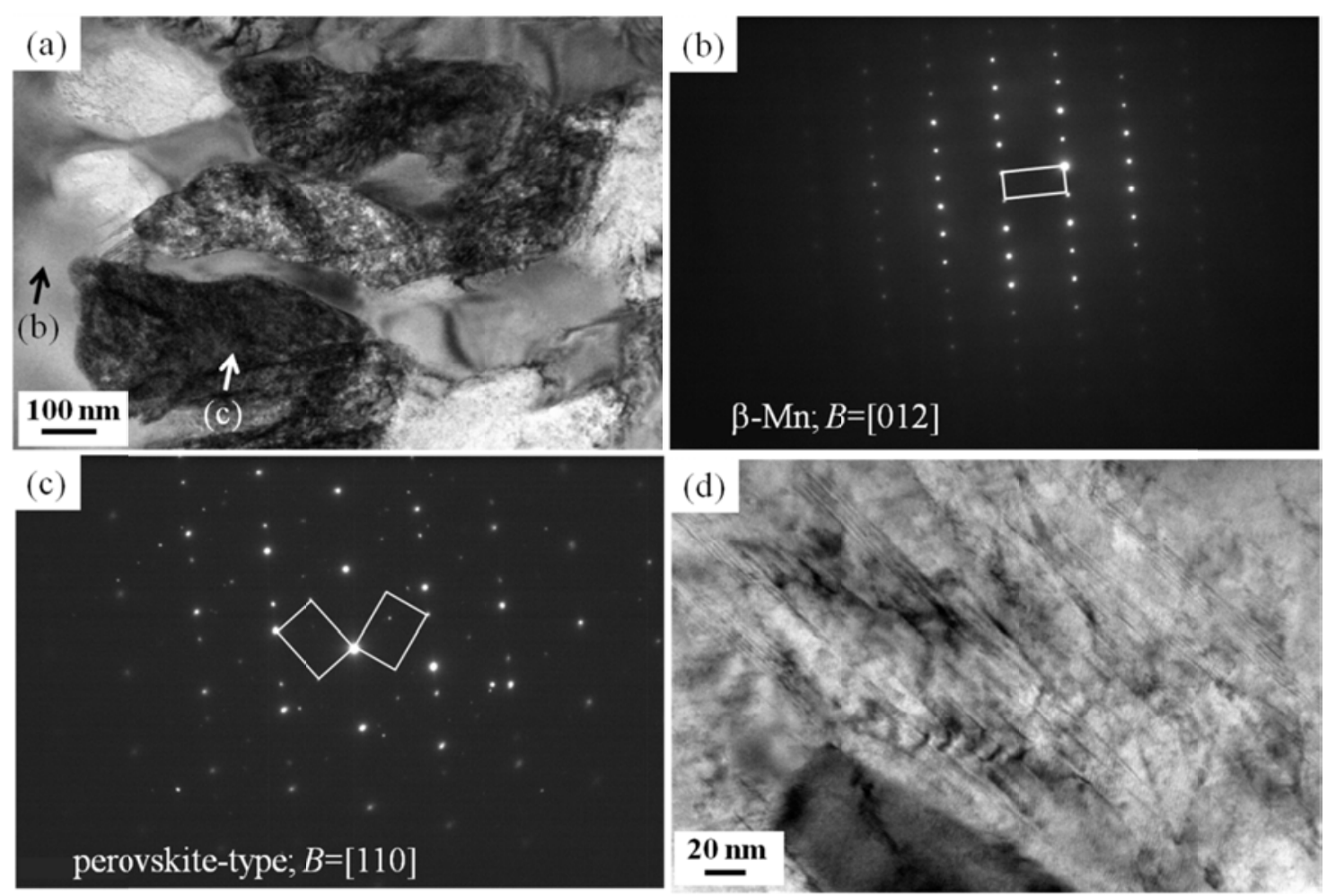

Fig. 8 (a) TEM image of the $\mathrm{Mn}-\mathrm{Sn}-\mathrm{Co}-\mathrm{N}$ alloy annealed at $500{ }^{\circ} \mathrm{C}$, and $\mathrm{SAD}$ patterns for the regions that indicated by the (b) black arrow and (c) white arrow in (a). (d) Magnified TEM image of the region indicated by the white arrow. 


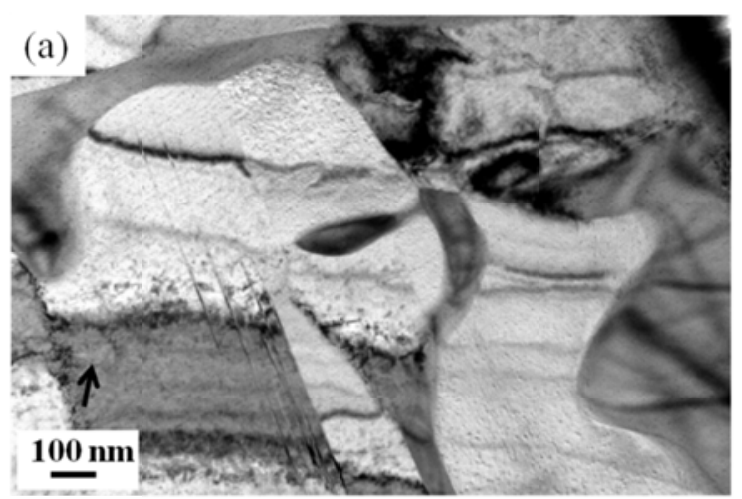

(b)

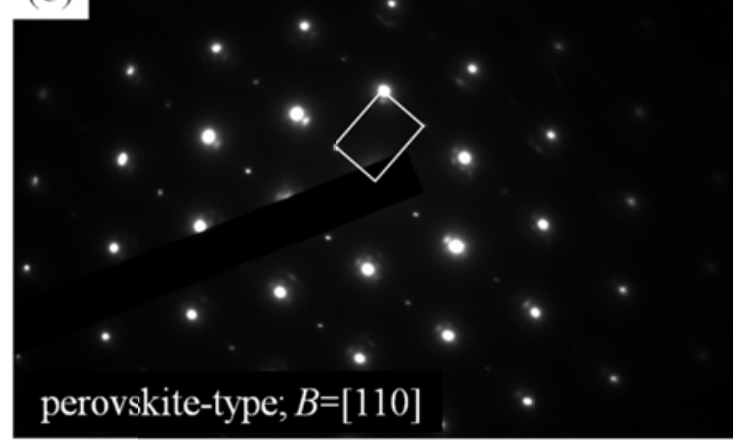

Fig. 9 (a) TEM image and (b) SAD pattern taken from the regions indicated by the black arrow in (a). 